\title{
O corpo do/no discurso midiático das dietas: efeitos do novo e da novidade ${ }^{1}$
}

\section{The body of/in the media discourse of diets: effects of new and novelty}

\author{
Lucília Maria Abrahão e Sousa \\ Universidade de São Paulo (USP) \\ <luciliamasousa@gmail.com>
}

Rodrigo Daniel Sanches

Universidade de São Paulo (USP)

<rodrigo.dsa@gmail.com>

\section{RESUMO}

A pesquisa busca refletir, na perspectiva teórica da Análise do Discurso (Pêcheux, 2009; Orlandi, 2012), em interface com as Ciências Sociais, sobre o sujeito e os efeitos de sentido produzidos pelo discurso midiático de dietas e suas novidades. O corpus é composto por revistas e sites que promovem as novas dietas. Nossa hipótese é a de que o discurso midiático das novas modalidades de regime afeta a constituição do sujeito e sua relação com o corpo. Esse discurso, com linguagem ancorada em simbolismos, promete que o novo (dieta, exercício) por si só, é e será sempre o melhor, mesmo com o surgimento de coisas novas em velocidade incompatível com a capacidade dos sujeitos de consumi-las e entendê-las em sua totalidade. $\mathrm{O}$ discurso midiático do mercado da dieta faz circular sentidos de um corpo-projeto que contrastam com a obsolescência do corpo real. O sujeito é convocado a viver na encruzilhada entre a excelência imposta pelas ferramentas midiáticas e a imperfeição da realidade.

Palavras-chave: Corpo. Dietas. Mídia.

\begin{abstract}
The present research seeks to investigate and reflect, at the interface of the theoretical perspective of Discourse Analysis (Pêcheux, 2009; Orlandi, 2012) and the Social Sciences, the subject and the effects of meaning produced by the media diets discourse and their supposed novelties. The research corpus is composed of magazines and websites that promote new diets. Our hypothesis is that the discourse of the new diets affects the constitution of the subject and his relation with the body in the present time. This discourse, with a language always anchored in symbolism, promises that the new (the new diet, the new exercise) by itself, is and will always be the best, even if the emergence of new things occurs at a speed incompatible with the ability of Subjects to consume and understand them in their totality. The media discourse of the diet market circulates the meanings of a body-project that contrast with the obsolescence of the real body. The subject is convened to live at the crossroads between the excellence imposed by the media tools and the imperfection of reality.
\end{abstract}

Keywords: Body. Diets. Media.

Introdução: sobre efeitos ideológicos do corpo-perfeito (corpo-projeto)

A palavra "corpo" (do latim corpu) tem no dicionário uma série de significados, podendo representar "tudo o que tem expressão e forma", "a

1 Pesquisa financiada pelo CNPq. 
estrutura física do animal" ou "o cadáver humano" (Dicionário Michaelis, 2000, p. 591). Mesmo abarcando vários significados diferentes, o corpo que pretendemos trabalhar neste artigo não está dicionarizado. Enquanto corpo empírico, ele é apenas carne (Orlandi, 2012). O que nos interessa aqui vai "além da simples carne e simples unhas", como atestou Drummond (2004, p. 17), e nos impulsiona a investigar o corpo simbólico, produzido por um processo que é um processo de significação, um corpo interpelado, que não pode ser pensado sem a materialidade, a história e os processos da vida social e prática; portanto, o corpo não pode ser pensado sem a ideologia.

Na perspectiva da Análise do Discurso, teoria de matriz francesa que irá embasar este trabalho, a ideologia designa o que é o que deve ser, produzindo efeitos de evidência sobre o mundo e naturalizando um uso social tido como aceito para o hábito e o modo de inscrição do corpo. A ideologia é entendida como um mecanismo de produção de evidências que determina como as coisas são e como não são (Pêcheux, 2009). Segundo Mariani (1998), é um mecanismo imaginário através do qual se coloca para o sujeito, conforme posições sociais que ocupa, um dizer já dado como óbvio; um sentido que lhe parece evidente como, por exemplo, o formato magro do corpo que circula na mídia. Para Orlandi (2009), a ideologia é a condição para a constituição do sujeito e dos sentidos. Todo corpo necessita de um discurso que lhe dê uma forma, um desenho, uma possibilidade de se inscrever em uma determinada época e em uma determinada sociedade. E todo discurso necessita de um corpo. O discurso é a "palavra em movimento, prática de linguagem (...) é o lugar em que se pode observar essa relação entre língua e ideologia, compreendendo-se como a língua produz sentidos por/para os sujeitos" (Orlandi, 2009, p. 15). Não há história ou ideologia ou língua ou simbólico sem sujeito; portanto, não há história ou ideologia ou língua ou simbólico sem o corpo.

A busca por um determinado formato do corpo não é algo novo. A percepção que temos do corpo muda ao longo do tempo, e cada período e cultura têm sua obsessão com uma forma corporal específica. "Formas corporais desejáveis têm especificidades culturais, e os preconceitos se acumulam sobre aqueles cujos corpos são diferentes" (Foxcroft, 2013, p. 14). Esse corpo - argumenta Milanez (2009) - é produto de uma subjetivação marcada por uma alteridade constitutiva que abarca um conjunto de imagens e textos que nos remete a uma forma temporal determinada. O corpo é o meio pelo qual a conversão a nós mesmos se dá a ver, estabelecendo uma relação de si para consigo (Milanez, 2009).

No universo midiático das dietas, o corpo da mulher contemporânea é "discursivizado" como um corpo perfeitamente magro, o que aqui 
denominaremos "corpo-projeto", intrinsicamente ligado a um ideal de beleza naturalizado pela mídia. O corpo-projeto é um padrão de corpo gerado artificialmente por programas de computador e transformado em imagens idealizadas de uma perfeição inalcançável. Juntamente com uma linguagem trabalhada para persuadir o sujeito-leitor (como veremos mais adiante), ele traz consigo a ilusão de poder ser imitado, alcançado. E na autoilusão de tentar a todo custo modelar o corpo físico em algo metafísico, que não corresponde à realidade, o sujeito é exposto a uma série de armadilhas sedutoras provenientes de um discurso que se materializa em textos e imagens. Discurso que interpela ideologicamente o sujeito a fazer todo esforço para alcançar o corpo propagado em revistas e sites. Alguns dos artifícios disponibilizados pela mídia para que o sujeito modele seu corpo e alcance o padrão imposto pelo corpo-projeto são as novas dietas e suas supostas novidades.

Os blogs e revistas sobre "boa forma" e "vida saudável" trazem periodicamente um novo manual para emagrecer, muitas vezes endossado por celebridades de corpos esbeltos. Os tratamentos para perder quilos de forma rápida são diversos e mudam rapidamente, mas expõem características em comum: são lançados como a "última novidade", a mais "nova fórmula", imbuída da "mais recente descoberta". Podem ser novos exercícios, novos remédios, bebidas, alimentos ou novas maneiras de se alimentar (ou a combinação de vários métodos).

Para pensarmos a relação entre o corpo feminino e o discurso midiático das novas dietas e suas supostas novidades, adotamos os pressupostos analíticos, metodológicos e teóricos da Análise do Discurso (AD) de linha francesa. Em interlocução com autores e pesquisadores das Ciências Sociais, procuramos refletir sobre os efeitos de sentidos produzidos pelo discurso midiático das novas dietas, que prometem resultados rápidos e fáceis na busca de um corpo muitas vezes irreal. Para tanto, adotamos as noções conceituais de ideologia e Formação Discursiva (FD) provenientes da Análise do Discurso. A nossa hipótese é a de que o discurso midiático contemporâneo das novas modalidades de regime afeta a constituição do sujeito-mulher e sua relação com o corpo na contemporaneidade.

O corpus selecionado para este artigo é composto por recortes textuais dos seguintes periódicos e sites:

Publicações impressas:
1. Dieta Já;
2. Boa Forma;
3. Corpo a Corpo; 
4. Shape Brasil2;

5. Women's Health.

Sites:

6. corpoacorpo.uol.com.br;

7. mdemulher.abril.com.br.

A escolha dos periódicos teve como base três fatores: a abordagem das dietas para o público feminino e suas novidades; o tempo de permanência no mercado e, além da publicação impressa, dispor de versão online com espaço para comentário dos leitores e internautas. Optamos em trabalhar com revistas e sites sobre "boa forma" e "vida saudável" justamente por trazerem periodicamente um "novo" manual para emagrecer. A coleta do material para análise foi realizada da seguinte forma: 1. edições impressas: durante doze meses (de janeiro a dezembro de 2015), mensalmente ou de acordo com a periodicidade de cada publicação; 2 . versões digitais: durante doze meses (de janeiro a dezembro de 2015); 3. selecionamos os discursos midiáticos (textos) e os comentários dos leitores e sujeitos-internautas que fazem referência às "novas dietas e suas novidades".

Conforme argumenta Sousa (2009), um conjunto de discursos faz os corpos comportarem-se de uma determinada forma ou de outra, ou seja, modelos "discursivizados" desencadeiam formas-sujeito de um corpo perfeito (para determinados ambientes da esfera social). E a forma-sujeito histórica tem sua materialidade, diz Orlandi (2012, p. 87): "o indivíduo, interpelado em sujeito pela ideologia, traz seu corpo por ela também interpelado". Na perspectiva discursiva, a ideologia é uma prática que constitui, afeta e faz parte do processo de significação do corpo do sujeito (Orlandi, 2012). Podemos pensar na formasujeito corpo-operário (para os trabalhadores das fábricas); corpo-executivo (com seus ternos e gravatas de grife); corpo-cabide (modelos extremamente magras que servem de suporte para as roupas mostradas nas passarelas de moda); corpo-placa (homens-placas que anunciam produtos, mais comuns nas grandes cidades); corpo-wearable (corpo atraente não apenas para a passarela, mas para programas de TV, cinema, etc.), entre tantos outros. Não seria possível esgotar, em uma única pesquisa, a infinidade de formas-sujeito e seus corpos.

Nesse jogo, percebemos o funcionamento da ideologia legitimando o que deve ser compreendido como formato (imagem) do corpo contemporâneo. Ao relacionar sujeito/corpo/linguagem/sociedade, Orlandi (2012) atesta que

2 As publicações impressas foram coletadas durante 12 meses (janeiro a dezembro de 2015), o que não ocorreu com a Shape Brasil, cuja circulação foi interrompida em maio de 2015 (edição n. 69). Decidimos manter o periódico em nosso corpus por se tratar de uma importante e interessante amostra do discurso das dietas. 
podemos compreender como o corpo, pensando a materialidade do sujeito, sua historicidade, é significado em um ou outro espaço de existência, como o ambiente midiático das dietas e seus discursos. O sujeito é bombardeado por vários e conflitantes discursos, que, muitas vezes, se encontram em rota de colisão. Se por um lado ele é instigado a experimentar todo tipo de comida, com empresas de fastfood oferecendo promoções do tipo "2 em 1" ou "coma isso mais aquilo", por outro o sujeito é conclamado a ser magro a qualquer custo. É justamente essa ordem de contradição que nos interessa analisar nos dados que se seguem.

\section{Lipofobia: efeitos midiáticos da perda de peso}

A preocupação das sociedades contemporâneas em perder peso aumentou consideravelmente no último século e, segundo alguns psiquiatras, tornou-se um problema de graves proporções. A afirmação é da historiadora da medicina Louise Foxcroft, responsável por uma robusta pesquisa histórica sobre as dietas - A tirania das dietas: dois mil anos de luta contra o peso (2013). A história avassaladora das dietas começou nos tempos praticamente sem registros da pré-história, ganhando importância há aproximadamente 2 mil anos, quando os gregos desenvolveram uma maneira de enfrentá-la. Segundo a historiadora, teria sido o filósofo e médico grego Hipócrates (460-370 a.C.) um dos primeiros a pregar que os princípios subjacentes da saúde eram o alimento e o exercício. Todo o fundamento da ciência médica ocidental valia-se da diatetica - a terapia curativa fundamental de um regime com determinados alimentos. Portanto, ser muito gordo ou muito magro era um sinal de um corpo não saudável. A diatetica teria sido o fundamento antigo da ciência médica ocidental, uma terapia curativa essencial de um regime de condutas que prescrevia alimentos e maneiras específicas de comer (Foxcroft, 2013). Nesse contexto, a diatetica incluía a perda de peso somente quando necessária, e não por razões puramente estéticas.

O que torna, então, a era em que vivemos diferente de outros períodos históricos em relação ao corpo e à dieta? Dentre tantas outras diferenças, podemos dizer que a sociedade moderna é "gordofóbica" ou "lipofóbica". Lipofobia é um termo cunhado pela historiadora Mary Del Priore (Weinberg; Cordás, 2006) que significa odiar a gordura e o corpo gordo. Na mesma linha de raciocínio, Foxcroft (2013, p. 17-18) alerta que "temos uma aversão comum à gordura - uma'repulsa estética' que não deve ser confundida com preocupações com a obesidade e a saúde".

A preocupação em perder peso não se restringe ao mundo da moda ou a um nicho da sociedade. O psiquiatra Táki Athanássios Cordás e a psicanalista Cybelle Weinberg (2006) relatam que o aumento da incidência da anorexia nervosa 
nas últimas décadas teria como explicação as pressões sociais cada vez maiores para que as mulheres tenham um corpo magro, especialmente quando atuam em meninas jovens, numa idade em que elas são mais vulneráveis - ou quando as mesmas têm ocupações em áreas em que a forma e o tamanho do corpo são enfatizados (Weinberg; Cordás, 2006). O ato de fazer dieta não é algo recente. Segundo Foxcroft (2013), a palavra grega díaita, da qual deriva nossa palavra dieta, descrevia todo um modo de vida, fornecendo um caminho completo, mental e físico, para a saúde, a própria existência e o sucesso. No dicionário Michaelis, a palavra dieta é um substantivo feminino que pode significar:

1. Regime alimentício prescrito a um doente ou convalescente; 2. Privação de todos ou de alguns alimentos, em caso de doença; 3. Emprego metódico das coisas úteis para a conservação da saúde; 4. Predominância de um alimento na nutrição: Dieta láctea; 5. Cetogênica: dieta que fornece grande quantidade de gordura e quantidades mínimas de carboidratos; usada especialmente na epilepsia, para produzir cetose e alterar o grau de alcalinidade corporal (Michaelis, 2000, p. 721).

$\mathrm{Na}$ esteira da lipofobia e diferentemente do que consta no dicionário, a palavra "dieta", em sua versão midiática, assume outros efeitos de sentido que estão além da preocupação com a saúde e bem-estar ou a prescrição de determinados alimentos. Vejamos alguns recortes sobre dietas que circulam em nosso corpus de análise:

Recorte $1^{3}$ :

Dieta da proteína: enxuga 7 quilos em 14 dias

Dieta Dukan: elimina 5 kg em 15 dias

Dieta Nórdica: nova forma saudável de perder peso

Dieta Viking: - $2 \mathrm{~kg}$ por semana!

Dieta do GH: - 4 kg em 1 mês com cardápio que estimula o hormônio do crescimento

Dieta flex: - 4 kg em 30 dias. É só reduzir a carne do cardápio

- $3 \mathrm{~kg}$ por semana! com a dieta da sopa detox.

Barriga chapada com a dieta das castanhas. Elas acabam com a fome e reduzem a vontade por doces. Veja como usar na sua receita.

- 5 kg em 21 dias com direito a pé na jaca (grifos nossos) ${ }^{4}$

3 Procuramos reproduzir os textos de maneira mais fiel possível em relação à publicação original. Como as revistas e sites usam diferentes recursos de diagramação, nem sempre essa reprodução será exatamente igual. Para os comentários dos leitores/internautas, também procuramos manter a reprodução mais próxima do texto original.

4 Como dissemos anteriormente ao explicar os parâmetros usados na coleta dos dados, tanto o recorte 1 como os demais recortes que compõem nosso corpus foram selecionados a partir das 
As sequências discursivas acima mostram que as palavras de ordem "enxuga, elimina, reduzem", incorporadas à formação discursiva contemporânea sobre dieta, promovem um deslizamento para outros efeitos de sentidos que provavelmente são diferentes dos sentidos que os gregos atribuíam à dieta. A formação discursiva (FD) pode ser compreendida como o que, em um dado contexto sócio-histórico, define o que pode e deve ser dito, já que o sentido é afetado por meio da inscrição do discurso em uma determinada FD e não em outra(s), o que interfere na forma como o(s) sentido(s) são produzido(s) (Bastos, Garcia; Sousa, 2014). Uma FD não é atemporal, diz Indursky (1997), mas determina uma regularidade própria a processos temporais construindo um esquema de correspondência entre diferentes séries temporais.

Dependendo da Formação Discursiva na qual o enunciado está inscrito, teremos outras produções de sentidos, por isso o sentido sempre pode ser outro, mas nunca qualquer sentido (Bastos, Garcia; Sousa, 2014). Na FD do universo das dietas, os sentidos que circulam na mídia estão relacionados estritamente à perda de peso subjacente aos padrões corporais atuais, o que se marca pelo uso numérico de quilos a serem perdidos em um determinado número de dias. A perda de peso deve ser rápida, eficaz e definitiva, o que marca um modo de inscrição do tempo na contemporaneidade, qual seja, o tempo acelerado e com consequências próximas. A ideia em voga é subtrair: enxugar, eliminar, queimar ou perder peso; diminuir, saciar ou acabar com a fome; diminuir o número do manequim ou as medidas corporais.

Nas marcas linguísticas materializadas no dicionário para a palavra "dieta", não constam perda de peso ou diminuição da massa corporal. Ainda sobre a marca "dieta", anotamos que a denominação está sempre ligada ao funcionamento de um nome próprio que, como por efeito de autoridade, atribui imaginariamente importância e legitimidade ao programa de emagrecimento. Também observamos a partícula "de" acrescida de certo artigo definido, ou seja, "das castanhas", "da proteína”, "da sopa”, o que marca um alimento ou receita que seria capaz de assegurar o emagrecimento e se tornaria de saída a solução para o problema do peso. Em comum, tais sequências reiteram que os efeitos de sentidos das dietas têm como objetivo fazer desaparecer ou definhar as formas corporais até o "tamanho zero", expressão usada pela modelo Kate Moss que demonstra o culto ao estilo que tomou conta do universo das passarelas e da mídia nos últimos anos.

seguintes Fontes: revistas impressas (Dieta Já, Boa Forma, Corpo a Corpo, Shape Brasil e Women's Health) e sites (corpoacorpo.uol.com.br e mdemulher.abril.com.br). A coleta do material para análise foi realizada durante doze meses (de janeiro a dezembro de 2015). 
Um dos aspectos contraditórios que podemos observar em uma das chamadas acima é a sugestão de que é possível perder peso rapidamente (- 5 kg em 21 dias) ingerindo todo tipo de alimento e em qualquer quantidade (com direito a "pé na jaca"). Na práxis do universo midiático das dietas, os sentidos transmitem a ilusão de que é possível emagrecer de forma fácil e rápida (como também veremos mais adiante). A expressão “pé na jaca” do recorte acima evoca efeitos que remetem ao exagero, dando uma espécie de "permissão" ao sujeito para que cometa abusos ou excessos alimentares, o que entra em choque com a possibilidade de emagrecer de forma rápida.

As contradições não param na chamada de capa. O interior do texto mostra a rotina de uma atriz para manter a forma. Em um dos trechos há o subtítulo "Menu Light", seguido da seguinte narrativa:

Recorte 2:

Filha de pai gaúcho e mãe pernambucana, Paloma revela que na sua casa é uma mistura de tapioca, churrasco, rabada, queijo coalho, e ela come de tudo

É como se o sujeito pudesse emagrecer ingerindo em algum momento alimentos de altovalor calóricoe em grandesquantidades, o que vaina contramão das restrições impostas pelas dietas que circulam no ambiente midiático.

\section{A nova dieta: surfar nas ondas das novidades}

Uma vez que todo discurso se estabelece na relação com um anterior e aponta para outro, a análise de discurso ajuda a compreender como uma determinada prática discursiva e, consequentemente, o seu discurso (no caso, o novo e a novidade) funciona produzindo efeitos de sentidos. Poderíamos dar inúmeros exemplos do discurso midiático do novo e da novidade (um deles é o universo automotivo - Sanches; Sousa, 2014). No presente artigo vamos focar nossa análise do novo e da novidade no universo das dietas. 0 permanente diálogo entre máquinas e pessoas que configura o mundo on-line e a instantaneidade do espaço virtual configuram aspectos fundamentais para a criação e circulação do discurso das novas dietas e suas supostas novidades. O que se procura envelhecer, no entanto, são os próprios vetores simbólicos presentes no discurso do lançamento de um determinado produto, ideia ou serviço. Aquilo que foi divulgado como sendo a última novidade, a mais recente tecnologia, em pouco tempo é substituído por outros atributos, que torna aquilo que era novidade em algo velho e ultrapassado, em um "moto-contínuo". 
O discurso midiático do novo e da novidade produz sentidos no universo real e imaginário, tendo como base alguns parâmetros e fundamentos ${ }^{5}$ desse mesmo discurso:

1 - só o que é novo, na sociedade contemporânea, é eficaz;

2 - para ser desejado, necessita ser rapidamente atualizado;

3 - o quanto a satisfação gerada por um produto, ideia ou serviço é fugaz;

4 - o quanto um produto, ideia ou serviço é perecível;

5 - o quanto a novidade é construída a despeito da vida útil do produto, ideia ou serviço (Sanches; Sousa, 2014, p. 66).

Foxcroft (2013, p. 41) alerta que atualmente há sempre um novo manual de dieta nas listas de livros ${ }^{6}$ mais vendidos, e muitos deles promovem regimes insustentáveis ou versões requentadas de modismos anteriores, com frequência endossados por alguma celebridade cujo corpo inatingivelmente esbelto denuncia horas de trabalho e um bocado de investimento financeiro.

A cada edição das revistas e sites de boa forma, uma infinidade de novidades faz circular sentidos que exaltam a velocidade/imediatismo para emagrecer, a facilidade (a suposta possibilidade de emagrecer com receitas rápidas e fáceis ou exercícios que podem ser praticados no ambiente de trabalho), entre outros aspectos. Foxcroft (2013) argumenta que as novas dietas são tentadoras ao prometerem uma perda de peso livre de tensões, indolor e de forma imediata. Aqui observamos uma das contradições atreladas à FD do corpo-projeto: fazer dieta é um processo muito mais complexo do que a mídia faz parecer. Cada dieta é lançada como uma "novidade" ou, em outras palavras, com um "diferencial". Vejamos alguns exemplos:

Recorte 3:

É moda na Europa! Nova dieta alterna minijejum com dias de até $1.500 \mathrm{kcal}$ SUPER NOVIDADE! DIETA NÓRDICA. - 4 kg em um mês. Copie o prato das mulheres + magras do mundo

Novas fórmulas para emagrecer

Dieta nórdica: nova forma saudável de perder peso

A nova Dieta Dukan é mais fácil e tão eficiente quanto a original

5 Sabemos que, para a análise do discurso, os efeitos de sentido podem sempre ser outros. A expressão "fundamento" é empregada como alicerce da ideologia dominante do novo e da novidade, que faz circular efeitos de sentido através da mídia na divulgação de produtos, ideias e serviços, em especial àqueles voltados para o consumo.

6 Em 2014, um dos livros mais vendidos no país era "Eu não consigo emagrecer", escrito pelo médico francês Pierre Dukan. A obra figurava há 81 semanas entre os 10 livros mais vendidos na categoria "Autoajuda e Esoterismo" de uma revista de grande circulação. Disponível em: http://veja.abril.com.br/ livros_mais_vendidos/ Acesso em: 6 mai. 2014 
A nova dieta que é febre entre as famosas

Nutricionista revela nova dieta da Bruna Marquezine

Esses recortes nos dão pistas da maneira como o discurso do novo e da novidade opera produzindo sentidos através do seu fundamento número 1 (só o que é novo, na sociedade contemporânea, é eficaz). Pelo simples fato de ser (aparentar ser) uma novidade, as novas dietas apresentam-se como milagres na busca pelo emagrecimento, prometendo fórmulas mágicas de se alcançar o corpo-projeto. A "nova dieta Dukan" do recorte acima foi publicada no site mdemulher.abril.com.br em 6 de abril de 2015 (atualizado em 13 de abril do mesmo ano), e gerou o seguinte comentário de um sujeito-leitor: (Recorte 4) "Estou na fase cruzeiro da ducan original, será que posso mudar para nova dieta ducan?"

Oito meses antes, a edição de agosto de 2014 da Revista Shape trazia em sua capa7: (Recorte 5) “Exclusivo! Nova dieta Dunkan! - 1 kg por semana! (mais fácil de seguir!)".

O sujeito-leitor que se apoia no discurso midiático das dietas para tentar emagrecer, sendo interpelado pela ideologia da magreza e atreladas às formações discursivas das dietas e do corpo-projeto, provavelmente faz um esforço para acompanhar tantas novidades. São inúmeros os exemplos do novo e da novidade no discurso das dietas. As próprias dietas anunciadas como novas são, em muitos casos, reedições de versões anteriores. "Novas dietas vão e vêm, mas sempre são reelaborações do passado, e o mesmo é válido para alguns dos produtos mais bizarros no mercado do emagrecimento" (Foxcroft, 2013, p. 239). Outros efeitos de sentidos também podem ser percebidos nos enunciados acima, evocando, por exemplo:

1. Superioridade, alto grau de sofisticação (atrelar a novidade a um país ou continente supostamente mais desenvolvido que o nosso, como"supernovidade nórdica" ou a "moda europeia" da alternância de jejum e ingestão de um número específico de calorias);

2. Velocidade, rapidez, imediatismo (- 4 kg em um mês);

3. Comparação (ao sugerir que as mulheres mais magras do mundo são as nórdicas, e não as brasileiras);

4. Modismos (a nova dieta é febre entre as famosas, sempre magras, com seus corpos perfeitos).

5. Facilidade (A nova dieta Dukan é mais fácil e tão eficiente quanto a original).

7 Mesmo não fazendo parte do nosso corpus, que abrange as notícias publicadas entre janeiro e dezembro de 2015, usamos esse exemplo de 2014 para mostrar como a dieta Dukan é constantemente reeditada e renovada pelo discurso midiático. 
Os efeitos atrelados ao discurso midiático das dietas marcam o processo de emagrecer como algo fácil de fazer e rápido na geração de resultados. Segundo Foxcroft (2013, p.18), "fazer regime é um processo no qual a pessoa embarca carregada de emoções, muitas vezes com uma postura de autoflagelação, e o empreendimento todo é temperado com o potencial para o fracasso". Os recortes 4 e 5 também indiciam o modo como o sujeito-leitor parece ser arremessado de um lado para outro pelas ondas das novidades do oceano midiático das dietas. $O$ sujeito do discurso das dietas, que "surfa nas ondas" do novo e da novidade, é o sujeito que, conforme explica Bauman, para não afundar está sempre surfando:

O truque é manter o ritmo com as ondas. Se não quiser afundar, mantenha-se surfando - e isso significa mudar o guarda-roupa, o mobiliário, o papel de parede, o olhar, os hábitos, em suma, você mesmo, quantas vezes puder. Eu não precisaria acrescentar, uma vez que isso deva ser óbvio, que essa ênfase em eliminar as coisas - abandonando-as, livrando-se delas -, mais que sua apropriação, ajusta-se bem à lógica de uma economia orientada para o consumidor (Oliveira, 2009, s/p, grifos nossos).

Bauman (1998) nos diz que o que vemos na sociedade atual é um processo de "mercadorização", no qual ocorre simultaneamente o ato de nascimento do consumidor: mercadorias potenciais e compradores potenciais realizam-se juntos. Assim também ocorre com as dietas: há um entrelaçamento do sujeitoleitor com as dietas, não as de ontem ou de anteontem ou do mês passado, mas as novas dietas, aqueles que estampam a edição mais atual da revista ou site de boa forma. "Surfar nas ondas" das novidades instituídas pelo discurso midiático é uma necessidade das massas contemporâneas. Provavelmente as celebridades que endossam as dietas da moda possuem um arsenal de profissionais (nutricionistas, preparadores físicos, médicos, entre outros) muito bem remunerados e que não estão ao alcance da maioria da população para manter seus corpos perfeitos (sem falar na manipulação digital empregada na construção das imagens midiáticas do corpo-projeto). O novo também aparece nas diversas práticas de emagrecimento, como a alimentação:

Recorte 6:

Novos superalimentos sem glúten!

Tomate no jantar queima calorias (...) Adote esse novo hábito e perca 3 kg em um mês.

O novo chá aliado da dieta.

Refeições com calorias negativas. Elas são a nova escolha dos nutricionistas para emagrecer de forma rápida. 
Ataque às últimas gordurinhas. Firme na dieta? Para dar um novo impulso à perda de peso, o cardápio começa com uma semana detox.

Outros exemplos da novidade são os aparelhos, aplicativos ou procedimentos estéticos para emagrecer:

Recorte 7:

Especial beleza: 10 Supernovidades para Rosto e Corpo (a Ciência Comprova).

Projeto antipneus (...) Novos aparelhos que derretem a gordurinha.

Novo aplicativo Atitude Boa Forma. O aliado perfeito para o seu projeto de vida saudável.

Novo programa oferece detox de sete dias para acelerar o emagrecimento.

As novas pílulas naturais para emagrecer.

Novas proteínas para emagrecer. Saia da mesmice com a inclusão de duas carnes diferentes na rotina.

Dê folga para a esteira! A nova aeróbica pode ser feita em casa, na praia, na rua, na praça... e queima 700 calorias (grifos nossos).

As revistas de boa forma e vida saudável atuam no contexto midiático legitimando um ideário sobre o corpo-projeto e como fazer para alcançá-lo. É difícil caracterizar as revistas e sites de boa forma quanto ao seu conteúdo. Os textos e as imagens das revistas e seus pares virtuais (blogs, sites, redes sociais, entre outros) nos levam a crer que estamos diante de um discurso jornalístico que faz funcionar os sentidos de beleza, perfeição, magreza, atitude, vitalidade, jovialidade, entre tantos outros associados ao corpo-projeto. O deslizamento dos efeitos desentidosprovocadosporessas revistaspermite,nasarestas dos discursos, entrever o seu teor publicitário, uma publicidade travestida de jornalismo.

O uso da palavra "detox" ("Novo programa oferece detox de sete dias") está atrelada a uma série de possibilidades dietéticas:"semana detox", "programa detox", "suco detox", "alimento detox", "dieta detox". Ao acrescentar o adjetivo "novo" à expressão "detox", mais possibilidades para emagrecer são colocadas à disposição do sujeito. A palavra "detox" como um dos recursos para perder peso é oriunda da língua inglesa, uma maneira informal e abreviada da expressão detoxification (o processo de remover substâncias tóxicas de um determinado organismo) como o corpo.

Ao atribuir a determinados alimentos ou exercícios o efeito de "desintoxicar" o corpo, o discurso midiático das dietas faz circular efeitos de sentidos de que o processo de emagrecimento passa por uma "limpeza" do organismo. O corpo magro, esbelto, é um corpo "limpo", livre de toxinas e, desta forma, saudável. Os efeitos de sentidos sobre o gordo e a gordura são relacionados a um organismo "envenenado", "intoxicado". Gordo - ressalta 
Foxcroft (2013) - é um sinônimo para os imprestáveis, lentos, inertes, fracos, pobres, burros e sem atrativos. E também "intoxicados". No entanto, "o corpo não se desintoxica com suco", afirma a nutricionista e professora Sophie Deram (Vines, 2016).

Os efeitos de sentidos do discurso midiático das dietas, relacionados à formação discursiva da dieta enquanto procedimento ligado estritamente à perda de peso, são potencializados por recursos linguísticos como "detox", "superalimentos", "supernovidades", "projeto antipneus" e tantas outras expressões que, como dissemos anteriormente, permitem entrever sua veia publicitária.

Outro aspecto contraditório que chama nossa atenção no discurso midiático das dietas é a forma sujeito corpo-(re)fabricado, que faz parecer natural um processo de renovação do corpo (contrário ao processo natural de envelhecimento), mantendo-o sempre magro e jovem, como se fosse possível estancar as marcas que o tempo imprime ao sujeito. Não apenas as dietas ou objetos devem ser sempre novos, mas o corpo deve renovar-se para manterse sempre "novo". Não há espaço para o "corpo-velho", de aspecto enrugado. A ideologia do "corpo-sempre-jovem" materializa-se na linguagem midiática da forma sujeito "corpo-renovado", que não pode envelhecer, não pode apresentar rugas, sinais de cansaço, olheiras, marcas do tempo, como podemos ver nos próximos recortes:

Recorte 8:

Corpo novo a partir de $\mathrm{R} \$ 85$. Ataque a celulite, gordura, estrias...

Seu rosto pede uma pele nova.

Ano novo, corpo novo. Não espere o carnaval passar para começar o ano de verdade.

Jovem para sempre. O cardápio que previne e combate cabelos brancos e linhas de expressão (de quebra, seca 5 kg em 1 mês!). (Grifos nossos).

A ideologia do corpo-projeto interpela o sujeito-leitor de modo a não deixar espaço para a circulação de vários sentidos sobre o seu próprio corpo: deve ser magro, e não gordo; deve ser rápido e ágil, e não devagar ou desajeitado; deve ser belo, e não feio; deve ter sempre um aspecto jovem, nunca velho. Nos recortes acima, percebemos como o sujeito-leitor é interpelado a se inscrever em uma formação discursiva de renovação do corpo - tudo aquilo que remete ao processo natural de envelhecimento deve ser submetido a ações de rejuvenescimento.

Outros efeitos atrelados à FD das dietas e do "corpo-renovado" apontam para um processo sempre disponível e que não exige muitos gastos. Um exemplo é a chamada de capa "Corpo novo a partir de R\$ 85", o que remete a efeitos de 
que o corpo é algo descartável, que pode ser comprado no balcão de uma clínica de estética por um preço acessível. Quando sabemos que os procedimentos estéticos são relativamente custosos e a indústria da dieta explora um lucrativo negócio (Foxcroft, 2013). "Ano novo, corpo novo" e "Corpo novo, vida nova" também são expressões publicitárias (e não jornalísticas) que remetem a efeitos de renovar, substituir algo velho por um sistema novo, rejuvenescido. No entanto, ao insistir no processo de renovação do corpo, o discurso midiático apaga o processo de envelhecimento natural desse mesmo corpo, fazendo desaparecer a sua obsolescência, mantendo uma busca insaciável por produtos e regimes que permitam ao sujeito ser "jovem para sempre".

As marcas da pele e suas linhas de expressão (estrias, celulite, manchas, cicatrizes) devem ser combatidas, assim como os cabelos brancos. Não importa a idade: os métodos para manter-se sempre jovem e, portanto, "atualizado", estão à disposição do sujeito. No discurso midiático das novas dietas não há espaço para outros dizeres: um corpo ostentando marcas do tempo ou acima do peso possuem pouco ou quase nenhum espaço nas revistas ou sites de boa forma.

No Dicionário Michaelis de Língua Portuguesa (2000, p. 1467), uma das definições para o adjetivo novo é "aquilo que tem pouco uso". No entanto, inúmeros produtos tornam-se obsoletos antes de perderem sua razão de uso, ou seja, não porque deixaram de funcionar adequadamente ou não realizam mais a função a que se destinam pelo desgaste natural de seus componentes, mas sim pelo envelhecimento imaginário imposto pelo discurso publicitário/ midiático. As dietas, assim como os produtos, tornam-se obsoletas rapidamente por serem suplantadas por outra grande ideia para emagrecer.

As palavras, expressões, discursos, anúncios, publicidade e propaganda, informações jornalísticas, entre outras formas de produção e disseminação de informações, recebem seu sentido da formação discursiva na qual são produzidas. O discurso do novo e da novidade na divulgação das dietas e práticas de emagrecimento faz parte de um conjunto de mecanismos linguísticos que, de acordo com Pêcheux (2009, p. 148), "se constituem sóciohistoricamente sob a forma de pontos de estabilização que produzem o sujeito, com, simultaneamente, aquilo que lhe é dado ver, compreender, fazer, temer, esperar etc".

Ao consumir as informações sobre as novas dietas e praticar o que elas propõem, o sujeito é interpelado pela formação discursiva dominante (no caso, só aquilo que é novo é bom), através da "identificação (do sujeito) com a formação discursiva que o domina (isto é, na qual ele é constituído como sujeito)" (Pêcheux, 2009, p. 150). A necessidade de envelhecer coisas e conceitos faz parte de uma lógica do capitalismo para vender cada vez mais: mais revistas, 
mais visualizações nos sites, mais produtos e procedimentos estéticos, mais cirurgias estéticas, mais alimentos "funcionais" que prometem saciar a fome sem engordar. Mais, mais e mais: é a lógica a que está submetido a forma histórica sujeito-capitalista. A ideologia do mercado cria uma realidade midiática que acelera o tempo e envelhece coisas (palpáveis e não palpáveis), que muitas vezes são descartadas para dar lugar ao último lançamento, aquilo que é mais recente, em uma lógica do capitalismo e do consumo (Sanches; Sousa, 2014).

\section{Considerações finais: a escalada da obsolescência das dietas (e do corpo)}

Ao fazer uso do corpo como suporte sígnico para sua própria linguagem, a mídia idealiza um corpo ideal, um corpo-projeto (para o que se pretende anunciar/divulgar). Nesse mecanismo imaginário (portanto simbólico) o sujeito se imagina uno, fonte do dizer e senhor de sua língua. Dessa forma, apaga-se para o sujeito o fato de ele entrar nessas práticas histórico-discursivas já existentes (como a ideologia do corpo-projeto presente nos discursos publicitários e midiáticos das dietas).

É a ideologia que tece a trama de que certos dizeres estão autorizados a serem tomados como próprios pelo/do sujeito em determinadas condições sócio-históricas, a partir do lugar de onde ele fala e das regiões de poder implicadas nesse falar. Orlandi (2012) pontua que a ideologia não aparece como ocultação, nem tem um sentido negativo; também não se trata de uma falsa consciência ou uma pura alteridade, mas o modo através do qual os homens vivem suas relações em relação às suas condições de existência.

A imagem dos corpos da iconografia das dietas é manipulada digitalmente para obter requintes de magreza e perfeição, extinguindo-se qualquer defeito presente na verdadeira forma física. O corpo é esticado, os cabelos e a pele ficam mais brilhantes, os dentes são sempre branquíssimos. Essa imagem reverbera sentidos de evidência de um corpo perfeito, magro, liso, silenciando as imperfeições da realidade. A ideologia do corpo-projeto propagada pela mídia produz sentidos naturalizados como únicos possíveis, evidências que resultam em um processo de apagamento da materialidade do sujeito, já que a "evidência, produzida pela ideologia, representa a saturação dos sentidos e dos sujeitos produzida pelo apagamento de sua materialidade, ou seja, pela sua des-historicização" (Orlandi, 2009, p. 55).

Esse apagamento da materialidade do sujeito contemporâneo e a perda da relação com o real, essa complexa fusão corpo-imagem é algo extremamente perigoso: o sujeito coevo não deve (e é constantemente assediado para isso) estar acima do peso considerado aceitável não do ponto de vista da medicina, mas de um padrão estético propagado pela mídia. O sujeito é convocado a 
submeter-se "a qualquer sacrifício para apagar o tempo e suas marcas, escritas, sinais e cicatrizes" (Baitello, 2012, p. 91). A magreza, que já remeteu às doenças que enfeavam e matavam homens e mulheres (Priore, 2006), hoje é condição indelével da beleza.

A beleza midiática do corpo-projeto, que sustenta imaginariamente a FD do universo das dietas (com seu corpo-magro e atlético, de dentes brancos e cabelos sedosos e brilhantes, desprovido de rugas e cicatrizes e manchas e dobras e gorduras aparentes) e seus efeitos de sentido circulam na mídia e constituem um discurso que não dá margem a outros tipos de $\operatorname{corpos}^{8}$. Segundo Foxcroft (2013, p. 22), "a indústria das dietas investiu no pensamento mágico e na novidade e explora o lucrativo negócio de vender esperança a infelizes e desesperados e criar um círculo vicioso de desesperança".

A velocidade imposta pelo discurso do novo e da novidade corrói o tempo, tornando produtos (e os discursos que os validam e os legitimam) rapidamente obsoletos, alimentando a necessidade de mais novidades em um ritmo frenético (Sanches; Sousa, 2014). Pelo simples fato de ser (aparentar ser) uma novidade, as novas dietas apresentam-se como milagres na busca pelo emagrecimento, prometendo fórmulas mágicas de se alcançar o corpo perfeito. Elas são sempre mais fáceis e eficientes que suas coirmãs mais antigas: "A nova dieta Dukan é mais fácil e tão eficiente quanto a original". O discurso do novo e da novidade das dietas faz circular efeitos de sentidos de facilidade, rapidez, eficiência, em muitos casos relacionadas às celebridades, em uma escalada da obsolescência (sempre há uma nova dieta prometendo suplantar as anteriores).

Uma das especificidades da mídia na eficácia de interpelação dos sujeitos é que ela parece"não deixar espaços para além de si para nenhum outro discurso, para nenhuma outra forma de sujeito, para nenhum corpo que lhe sirva como suporte" (Payer, 2005, p. 19). Esse discurso usa uma linguagem sempre ancorada em simbolismos, promessas de que o novo (a nova dieta, o novo aparelho para eliminar gorduras ou o novo exercício) por si só, é e será sempre o melhor, mesmo que o surgimento de coisas novas ocorra numa velocidade incompatível com a capacidade dos sujeitos de consumi-las e entendê-las em sua totalidade. A ideologia do mercado das dietas faz circular sentidos de um corpo-projeto que contrastam com a obsolescência do corpo da realidade, tomando-o como

8 Sabemos que há, sim, outros modelos de corpos em circulação na mídia, "corpos-de-resistência", como o das modelos "plus size". No entanto, sua circulação é pequena, restrita a nichos específicas do ambiente midiático, ou em alguns casos fazem parte de movimentos de resistência ancorados em sites, blogs ou redes sociais destinadas a combater o modelo de beleza sugerido pela mídia. Reforçamos, no entanto, que o foco desta pesquisa é justamente os corpos que fazem circular sentidos no discurso midiático das dietas. 
um objeto frágil e obsoleto pela gordura que carrega (dobras e vincos), pelo processo de envelhecimento e pelas doenças que o castigam.

\section{REFERÊNCIAS}

BAITELLO JR., Norval. O pensamento sentado: sobre glúteos, cadeiras e imagens. São Leopoldo: Editora Unisinos, 2012.

BASTOS, Gustavo; GARCIA, Dantielle Assumpção; SOUSA, Lucília Maria Abrahão e. O discurso na rede eletrônica e o Google: o movimento LGBT em destaque. Revista RUA, Campinas, v. 20, n. 2, nov. 2014, p. 33-50.

BAUMAN, Zygmunt. $O$ mal-estar da pós-modernidade. Rio de Janeiro: Jorge Zahar Editor, 1998.

DRUMMOND, Carlos. Corpo: Novos Poemas. Rio de Janeiro: Record, 2004.

FOXCROFT, Louise. A tirania das dietas: dois mil anos de luta contra o peso. São Paulo: Três Estrelas, 2013.

INDURSKY, Freda. A fala dos quartéis e as outras vozes. Campinas: Editora da Unicamp, 1997.

MARIANI, Bethania. O PCB e a imprensa: os comunistas no imaginário dos jornais (1922-1989). Campinas: Editora da Unicamp, 1998.

MICHAELIS 2000: moderno dicionário da língua portuguesa. Rio de Janeiro: Reader's Digest, 2000.

MILANEZ, Nilton. A possessão da subjetividade: sujeito, corpo e imagem. In: SANTOS, João Bôsco Cabral dos (org.). Sujeito e subjetividade: discursividades contemporâneas. Uberlândia: EDUFU, 2009.

OLIVEIRA, Dennis de. Entrevista - Zygmunt Bauman. Revista Cult, on-line, 2009. Disponível em: https://revistacult.uol.com.br/home/entrevis-zygmunt-bauman Acesso em: 15 jan. 2017.

ORLANDI, Eni Puccinelli. Análise de Discurso: princípios e procedimentos. 8. ed. Campinas: Pontes Editores, 2009.

Discurso em análise: sujeito, sentido, ideologia. Campinas, SP: Pontes Editores, 2012.

PAYER, Maria Onice. Linguagem e sociedade contemporânea - sujeito, mídia, mercado. Revista RUA, Campinas, v. 11, n. 1, p. 09-25. set. 2005.

PÊCHEUX, Michel. Semântica e Discurso: uma crítica à afirmação do óbvio. Campinas, SP: Editora da Unicamp, 2009. 
PRIORE, Mary Del. Prefácio para a obra - Do altar às passarelas: da anorexia santa à anorexia nervosa. São Paulo: Annablume, 2006.

SANCHES, Rodrigo Daniel; SOUSA, Lucília Maria Abrahão. Admirável carro novo: o envelhecimento precoce de discursos e coisas. In: PATTI, Ane Ribeiro (e outros) (org.). Textecendo discursos na contemporaneidade. São Carlos: Pedro \& João Editores, 2014.

SOUSA, Kátia Menezes. O corpo enunciado e os movimentos de subjetivação e objetivação no reino do virtual. In: SANTOS, João Bôsco Cabral dos (org.). Sujeito e subjetividade: discursividades contemporâneas. Uberlândia: EDUFU, 2009.

VINES, Juliana. "O corpo não se desintoxica com suco", diz nutricionista da USP. Jornal Folha de S. Paulo, São Paulo, fev. 2016. Disponível em: http://achatadasdietas. blogfolha.uol.com.br/2016/02/11/o-corpo-nao-se-desintoxica-com-suco-diznutricionista-da-usp/. Acesso em: 5 jan. 2017.

WEINBERG, Cybelle; CORDÁS, Táki Athanássios. Do altar às passarelas: da anorexia santa à anorexia nervosa. São Paulo: Annablume, 2006.

Recebido em: 10/5/2017

Aceito em: $11 / 7 / 2017$

Dados dos autores

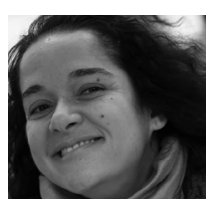

Lucília Maria Abrahão e Sousa | luciliamasousa@gmail.com

Doutora com dedicação exclusiva na Faculdade de Filosofia, Ciências e Letras de Ribeirão Preto da

Universidade de São Paulo (FFCLRP/USP), livre docente em Ciência da Informação (FFCLRP/USP).

Faculdade de Filosofia, Ciências e Letras de Ribeirão Preto da Universidade de São Paulo (FFCLRP/USP).

Avenida Bandeirantes, 3.900 - Vila Monte Alegre.

14040-900 - Ribeirão Preto (SP) - Brasil

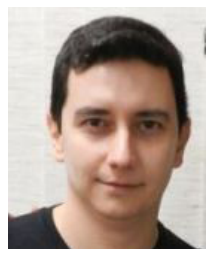

Rodrigo Daniel Sanches | rodrigo.dsa@gmail.com

Doutorando em Psicologia pela Faculdade de Filosofia, Ciências e Letras de Ribeirão Preto da Universidade de São Paulo (FFCLRP/USP), Mestre em Comunicação e Semiótica pela Pontifícia Universidade Católica de São Paulo (PUC/SP).

Programa de Pós-Graduação em Psicologia da Faculdade de Filosofia, Ciências e Letras de Ribeirão Preto da Universidade de São Paulo (FFCLRP/USP).

Avenida Bandeirantes, 3.900 - Vila Monte Alegre.

$14040-900$ - Ribeirão Preto (SP) - Brasil 